\title{
Preparação e caracterização de membranas cerâmicas tubulares de mulita
}

\section{(Preparation and characterization of tubular ceramic membranes of mullite)}

\author{
F.A.Silva', H.L.Lira', A. C. Chaves ${ }^{1}$, G. A. Neves ${ }^{1}$, K. B.França ${ }^{2}$ \\ ${ }^{1}$ Departamento de Engenharia de Materiais \\ ${ }^{2}$ Laboratório de Referência em Dessalinização - LABDES \\ Universidade Federal de Campina Grande, Av. Aprígio Veloso 882, Campina Grande, PB 58109-970 \\ falmeidasilva@gmail.com, helio@dema.ufcg.edu.br, alexsandrachaves@hotmail.com, \\ gelmires@dema.ufcg.edu.br, kepler@labdes.ufcg.edu.br
}

\begin{abstract}
Resumo
Os produtos cerâmicos são extremamente interessantes no campo das membranas por causa de sua resistência mecânica, inércia química, tempo de vida útil longa e estabilidade térmica. Atualmente as pesquisas estão sendo direcionadas para exploração destes materiais de baixo custo. Este trabalho consiste na preparação de membranas tubulares, obtidas a partir de composição contendo argila, caulim e óxido de alumínio, conformadas pelo processo de extrusão, utilizando diferentes temperaturas na etapa de sinterização para uso em microfiltração. Foi feita caracterização nas massas cerâmicas antes da sinterização, através dos ensaios de análise granulométrica, análise termogravimétrica, análise química e difração de raios X. A análise química mostrou altos teores de $\mathrm{SiO}_{2}$ e de $\mathrm{Al}_{2} \mathrm{O}_{3}$ e o ensaio de difração de raios X mostrou a presença de caulinita, quartzo e óxido de alumínio. Foi realizado ensaio de difração de raios $\mathrm{X}$ na massa após as sinterizações e os resultados mostraram a presença de mulita, óxido de alumínio e quartzo em todas as sinterizações efetuadas. Com relação ao tamanho e a distribuição destes poros nas membranas, os resultados da micrografia e de porosimetria por intrusão de mercúrio ilustraram a presença de poros em todas as temperaturas de sinterização, com dimensões na faixa de microfiltração. O ensaio de fluxo com escoamento tangencial utilizando água destilada mostrou que a membrana sinterizada a $1300{ }^{\circ} \mathrm{C}$ obteve o maior valor, seguida da de 1250,1200 e $1150{ }^{\circ} \mathrm{C}$.
\end{abstract}

Palavras-chave: membranas cerâmicas, matérias-primas, microfiltração.

Abstract

The ceramic products are extremely interesting in the field of the membrane supports because of their mechanical resistance, chemical inertia, long working life and thermal stability. Research is currently directed towards the exploitation of materials at a lower cost. The aim of this work is to prepare tubular ceramic membranes by extrusion using composition containing ball clays, kaolin and alumina and use different sintering temperatures, to be applied in microfiltration process. The characterization of the ceramic composition was performed before sintering: particles size, thermogravimetric analysis, chemical analysis and $X$-ray diffraction. The chemical analysis shows large content of $\mathrm{SiO}_{2}$ and $\mathrm{Al}_{2} \mathrm{O}_{3}$ and the $\mathrm{X}$-ray result shows the presence of kaolinite, quartz and alumina. The results from X-ray diffraction of the ceramic body after sintering show the presence of mullite, alumina and quartz. The SEM images and the results from mercury porosimetry show the presence of pores for all sintering temperatures and pore size in the range of microfiltration. The results from pure water flux, at steady state, show that the membranes sintered at $1300^{\circ} \mathrm{C}$ present the highest value, followed by the ones sintered at 1250,1200 and $1150{ }^{\circ} \mathrm{C}$.

Keywords: ceramic membranes, raw materials, microfiltration.

\section{INTRODUÇÃO}

Foram desenvolvidas membranas cerâmicas de cordierita, conformadas pelo processo de extrusão, utilizando quatro temperaturas de sinterização, objetivando mostrar a influência destas temperaturas nas características das membranas [1]. As membranas apresentaram poros com tamanhos de $1,4 \mu \mathrm{m}, 2,2 \mu \mathrm{m}, 3,3 \mu \mathrm{m}$ e $4,1 \mu \mathrm{m}$ e porosidade de $28,7 \%, 29,1 \%, 27,7 \%$ e $24,3 \%$, para as temperaturas de sinterização $1150,1200,1250$ e $1280{ }^{\circ} \mathrm{C}$, respectivamente, caracterizando-as como membranas para microfiltração.

Atualmente, o uso das membranas poliméricas é mais disseminado; no entanto, as membranas cerâmicas apresentam varias vantagens, tais como, melhor resistência mecânica, térmica e química [2]; entretanto, estas membranas são caras, levando em consideração as aplicações de separação de misturas menos nobres [3]. O alto custo de fabricação deve-se principalmente às matériasprimas que são importadas e sintéticas do tipo: zircônia, alumina, titânia e sílica e não são adequadas para aplicações em grande escala, especialmente em processos de separação que não envolvem produtos de alto valor agregado [4]. A região nordeste do Brasil possui grandes reservas de matérias-primas naturais que apresentam composição química adequada à produção de cerâmicas, podendo minimizar os custos de produção de membranas cerâmicas 
[5]. Alguns autores vêm desenvolvendo pesquisas onde mostram a utilização dessas matérias-primas na indústria cerâmica [6-7]. A utilização dessas matérias-primas naturais e sua transformação em produtos que possam ser comercializados ou que se mostrem economicamente viáveis, se apresentam como uma opção inovadora para as indústrias. Estes minérios possuem potencial de aplicação na obtenção de membranas cerâmicas, podendo ser submetidos ou não a um beneficiamento visando alterar suas características físicas. A utilização de membranas cerâmicas tem aumentado nas ultimas décadas e vem se transformado numa importante técnica de separação $[8,9]$.

Visando contribuir com a pesquisa tecnológica nesta área de concentração, neste trabalho foram produzidas membranas cerâmicas tubulares, utilizando composições com matérias-primas regionais de baixo custo e as sinterizando em diferentes temperaturas.

\section{MATERIAIS E MÉTODOS}

Materiais: para produção das membranas cerâmicas foram utilizadas as seguintes matérias-primas: argila ball clay, proveniente de Alhandra, PB, (44\%), caulim, proveniente do Junco do Seridó, PB, (21\%), e chamote, obtido após calcinação da argila ball clay a $1300{ }^{\circ} \mathrm{C},(35 \%)$.

Métodos: Inicialmente a mistura foi submetida à moagem a seco em moinho de bolas, tipo Bond, Marconi, MA 701/21. O tempo de moagem foi de $6 \mathrm{~h}$ a $40 \mathrm{rpm}$. Após a moagem a massa homogênea, em forma de pó, foi submetida a peneiramento em peneira ABNT 200 (abertura $0,074 \mathrm{~mm}$ ). Em seguida, a massa peneirada foi levada até um misturador planetário, Metvisa BAM12, no qual se adicionou água e aditivos líquidos até a obtenção de uma massa homogênea com plasticidade e umidade adequadas ao processo de extrusão. A umidade de processamento ficou em 19\%, medida por diferença de peso entre massa úmida e massa seca. A extrusão da massa cerâmica foi em extrusora a vácuo Verdés 051. A matriz tem formato anelar, com diâmetro externo do anel 10,9 mm e com um pino cilíndrico no centro, de diâmetro $7,7 \mathrm{~mm}$. As peças extrudadas adquirem formato tubular. Os tubos extrudados foram submetidos a duas etapas de secagem. Na primeira etapa as peças foram submetidas a uma secagem natural, durante 5 dias. $\mathrm{Na}$ segunda etapa foram levadas a uma estufa controlada em $95{ }^{\circ} \mathrm{C}$ onde ficaram durante $24 \mathrm{~h}$. Após a secagem, os tubos foram queimados segundo quatro curvas de queima. As queimas foram em forno elétrico Maitec. A fase de aquecimento durante o processo de queima das membranas foi feita baseando-se na curva da análise termogravimétrica (TG) da massa cerâmica. As taxas de aquecimento foram as seguintes: $2^{\circ} \mathrm{C} / \mathrm{min}$ a partir da temperatura ambiente até $400{ }^{\circ} \mathrm{C}, 1^{\circ} \mathrm{C} / \mathrm{min}$ de $400{ }^{\circ} \mathrm{C}$ até $700{ }^{\circ} \mathrm{C}$, e $3{ }^{\circ} \mathrm{C} / \mathrm{min}$ de $700{ }^{\circ} \mathrm{C}$ até atingir as seguintes temperaturas máximas (TM): (a) $1^{\text {a }}$ curva, $1150{ }^{\circ} \mathrm{C}$; (b) $2^{\mathrm{a}}$ curva, $1200{ }^{\circ} \mathrm{C}$; (c) $3^{\mathrm{a}}$ curva, $1250{ }^{\circ} \mathrm{C}$; (d) $4^{\text {a }}$ curva, $1300^{\circ} \mathrm{C}$. O tempo no patamar de sinterização de cada curva foi $1 \mathrm{~h}$. Após o patamar da etapa de sinterização, o forno foi desligado automaticamente, resfriando-se naturalmente por $12 \mathrm{~h}$.

A análise microestrutural das membranas cerâmicas foi feita por microscopia eletrônica de varredura, LEO 1430. O ensaio de porosimetria de mercúrio das membranas foi feito com equipamento Aminco 5000 OS.

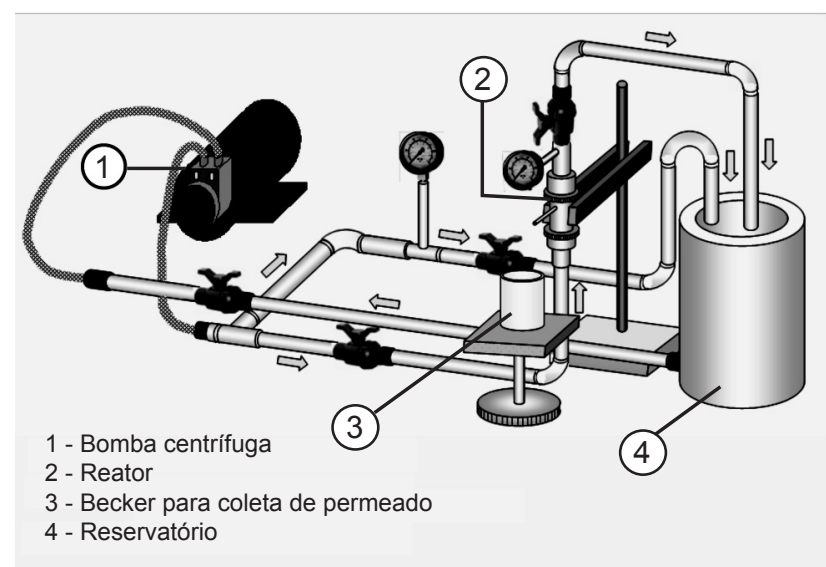

Figura 1: Representação esquemática do sistema de fluxo com escoamento tangencial.

[Figure 1: Schematic representation of the cross flow system.]

Para medida de fluxo com escoamento tangencial foi usado um sistema montado no Laboratório de Referência em Dessalinização na UFCG. AFig. 1 mostra uma representação esquemática deste sistema com escoamento tangencial. Foram testadas 12 amostras de membranas cerâmicas, sendo 3 de cada temperatura de sinterização.

\section{RESULTADOS E DISCUSSÃO}

A Fig. 2 apresenta a distribuição granulométrica das partículas da massa cerâmica antes da sinterização. Cerca de $36 \%$ da massa acumulada tem diâmetro médio equivalente $<3 \mu \mathrm{m}$ e $73 \%$ da massa acumulada tem diâmetro médio equivalente $<9 \mu \mathrm{m}$. Com base nesses valores [2], espera-se

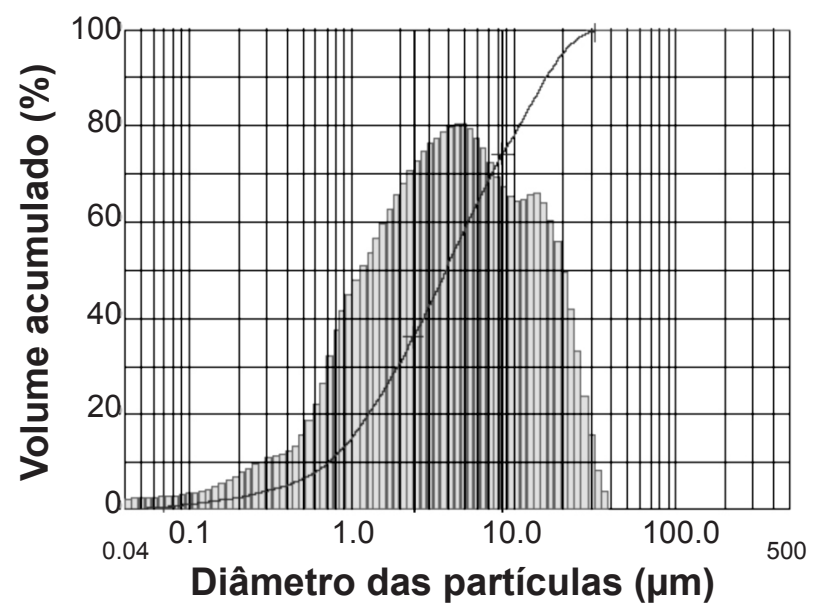

Figura 2: Distribuição granulométrica da massa cerâmica antes da sinterização.

[Figure 2: Particle size distribution of green ceramic paste.] 
obter membranas com poros na faixa de 0,1 a $5 \mu \mathrm{m}$.

A Fig. 3 ilustra as curvas da análise termogravimétrica realizada na massa cerâmica antes da queima. Observase uma perda de massa de $0,6 \%$ até $200{ }^{\circ} \mathrm{C}$, possivelmente relacionados à eliminação de água adsorvida e estrutural do material. De 200 a $400{ }^{\circ} \mathrm{C}$ uma pequena perda de massa, em torno de 1,4\%, consequência de perda de matéria orgânica. Entre 400 e $700{ }^{\circ} \mathrm{C}$ ocorre a maior perda de massa em todo o processo, $7,7 \%$, proveniente da perda de hidroxilas. A partir de $700{ }^{\circ} \mathrm{C}$ até $1000{ }^{\circ} \mathrm{C}$ ocorre uma perda de massa de $1,5 \%$. A perda total de massa foi de $\sim 11 \%$. A partir dessa análise foi possível determinar a curva de queima como foi descrito anteriormente.

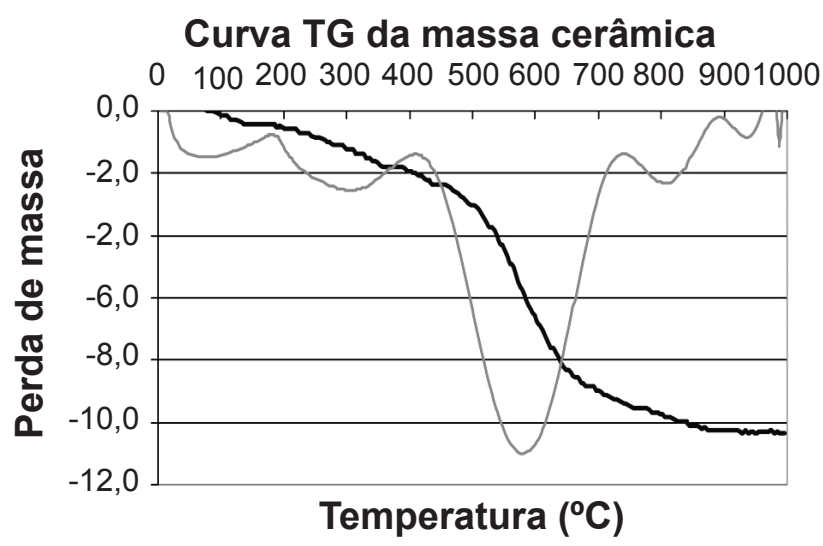

Figura 3: Curva de TG da massa cerâmica antes da sinterização. [Figure 3: TG curve of the green ceramic paste.]

A Tabela I apresenta a composição química da massa cerâmica antes da queima. A composição química apresenta altos teores de $\mathrm{SiO}_{2}$ e $\mathrm{Al}_{2} \mathrm{O}_{3}$ e um pequeno percentual de óxido de ferro $\left(\mathrm{Fe}_{2} \mathrm{O}_{3}\right)$. Os percentuais dos óxidos de potássio e de sódio são provenientes da argila ball clay e do caulim. A presença destes óxidos favorece a formação de fase líquida na etapa de sinterização durante o processo de queima.

Tabela I - Composições químicas das massas cerâmicas antes da queima.

[Table I -. Chemical composition of the raw materials and green ceramic paste.]

\begin{tabular}{lc}
\hline \multicolumn{1}{c}{ Óxidos } & $\begin{array}{c}\text { Percentual } \\
\text { em Peso }\end{array}$ \\
\hline Perda ao fogo $(\mathrm{PF})$ & 8,46 \\
Resíduos insolúveis $(\mathrm{RI})$ & 4,40 \\
Óxido de Silício $\left(\mathrm{SiO}_{2}\right)$ & 58,85 \\
Óxido de alumínio $\left(\mathrm{Al}_{2} \mathrm{O}_{3}\right)$ & 26,00 \\
Óxido de Ferro $\left(\mathrm{Fe}_{2} \mathrm{O}_{3}\right)$ & 1,36 \\
Óxido de cálcio $(\mathrm{CaO})$ & Traços \\
Óxido de Magnésio $(\mathrm{MgO})$ & 0,50 \\
Óxido de potássio $\left(\mathrm{K}_{2} \mathrm{O}\right)$ & 0,30 \\
Óxido de sódio $\left(\mathrm{Na}_{2} \mathrm{O}\right)$ & 0,06 \\
\hline
\end{tabular}

A Fig. 4 ilustra o resultado da difração de raios X da massa cerâmica antes do processo de queima.

O difratograma registra a presença de caulinita, caracterizada pelas distâncias interplanares de 7,15, 4,45, $3,57,2,48,2,33$ e $2,24 \AA$; de mica, caracterizado por 4,11 $\AA$; de óxido de alumínio, caracterizado por $2,55,2,38$ e 1,96 $\AA$ e de quartzo, caracterizado por $4,26,3,34,2,45,2,28,2,12$, 1,81 e $1,67 \AA$ A.

A Fig. 5 ilustra o resultado de difração de raios $\mathrm{X}$ da massa

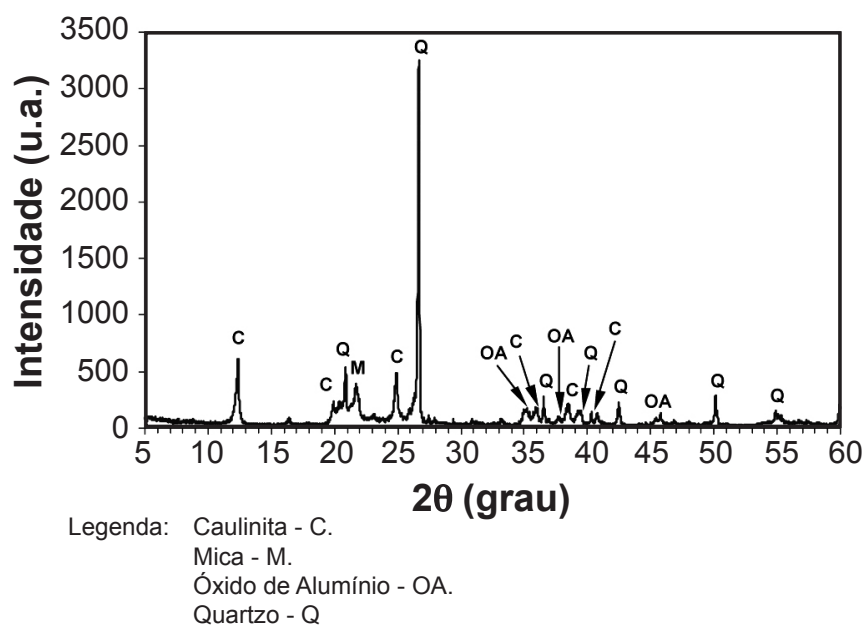

Figura 4: Difratograma de raios $\mathrm{X}$ da massa cerâmica antes da queima.

[Figure 4: X-ray diffraction pattern of the green ceramic paste.]

cerâmica sinterizada a $1150,1200,1250$ e $1300{ }^{\circ} \mathrm{C}$. Observase no difratograma a presença de quartzo, cristobalita, óxido de alumínio e de mulita, caracterizados pelos picos em

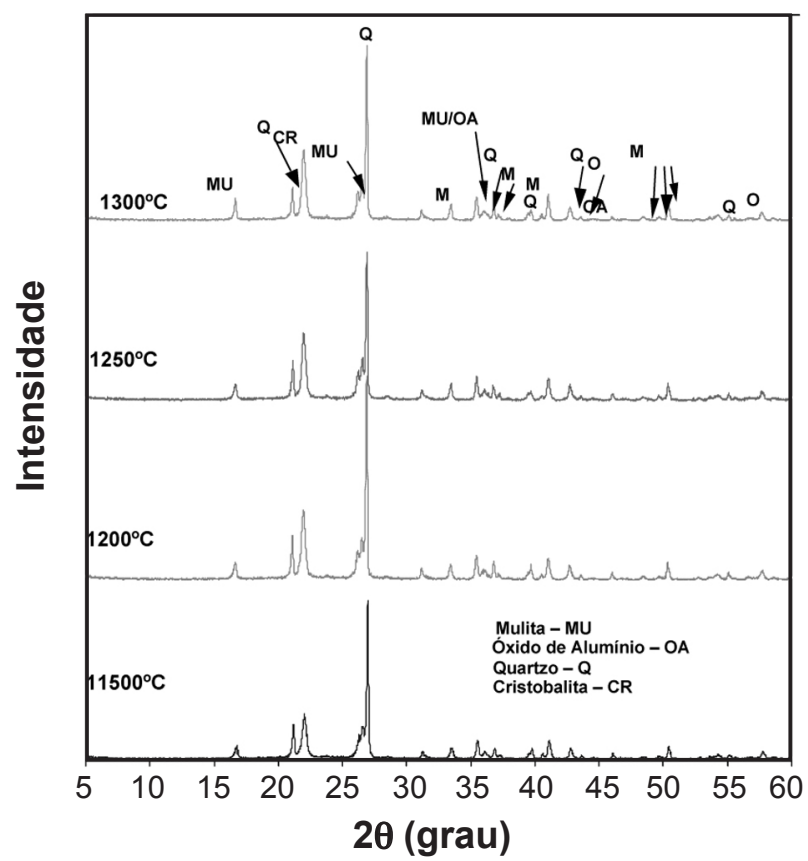

Figura 5: Difratogramas de raios X da massa cerâmica sinterizada a $1150,1200,1250$ e $1300{ }^{\circ} \mathrm{C}$.

[Figure 5: X-ray diffraction patterns of the ceramic paste sintered at $1150,1200,1250$ and $1300{ }^{\circ} \mathrm{C}$.] 
distância interplanar 5,40, 3,40, 2,70, 2,54, 2,42, 2,20, 1,86, 1,84 e $1,80 \AA$.

A Fig. 6 mostra as micrografias das secções longitudinais das membranas cerâmicas sinterizadas a 1150, 1200, 1250 e $1300{ }^{\circ} \mathrm{C}$. Verifica-se a presença de poros, com dimensões bastante variadas. Com o aumento da temperatura de $1150{ }^{\circ} \mathrm{C}$ para $1300{ }^{\circ} \mathrm{C}$ há uma mudança na característica morfológica na superfície da membrana, com o aparecimento de poros na forma de pequenas fissuras, principalmente em $1200{ }^{\circ} \mathrm{C}$ e $1250{ }^{\circ} \mathrm{C}$, diminuindo para a temperatura de $1300^{\circ} \mathrm{C}$ devido a maior formação de fase líquida com um maior grau de sinterização; estas observações não são conclusivas.

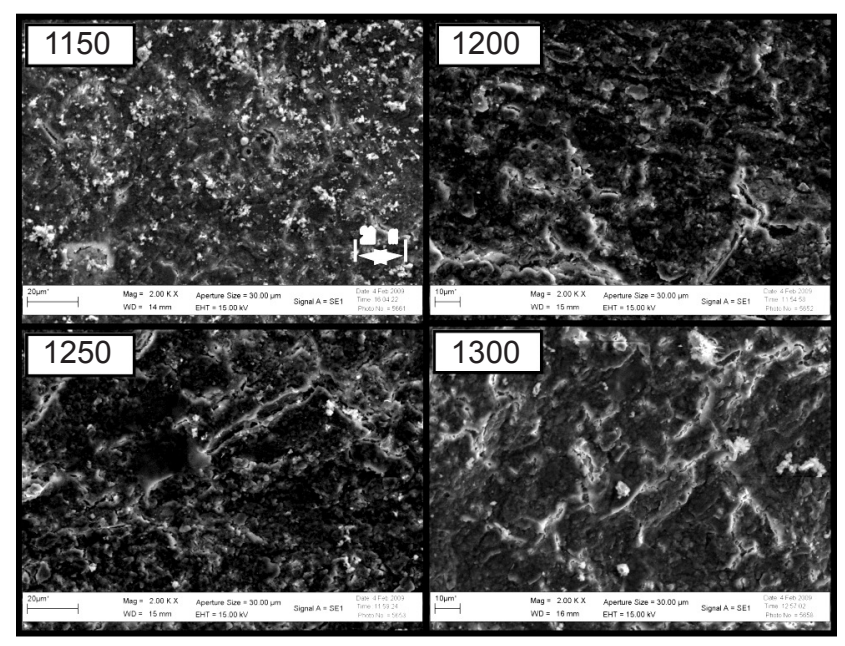

Figura 6: Micrografias obtidas em microscópio eletrônico de varredura da secção longitudinal das membranas cerâmicas.

[Figure 6: SEM micrographs of the longitudinal section of ceramic membranes.]

A Fig. 7 ilustra a variação do diâmetro de poros das membranas cerâmicas em função do volume de intrusão de mercúrio acumulado para as quatro temperaturas de sinterização. As quatro curvas apresentam a grande maioria de poros variando de 0,2 a $1,5 \mu \mathrm{m}$, sendo esta faixa de tamanho dos poros característica das membranas de microfiltração,

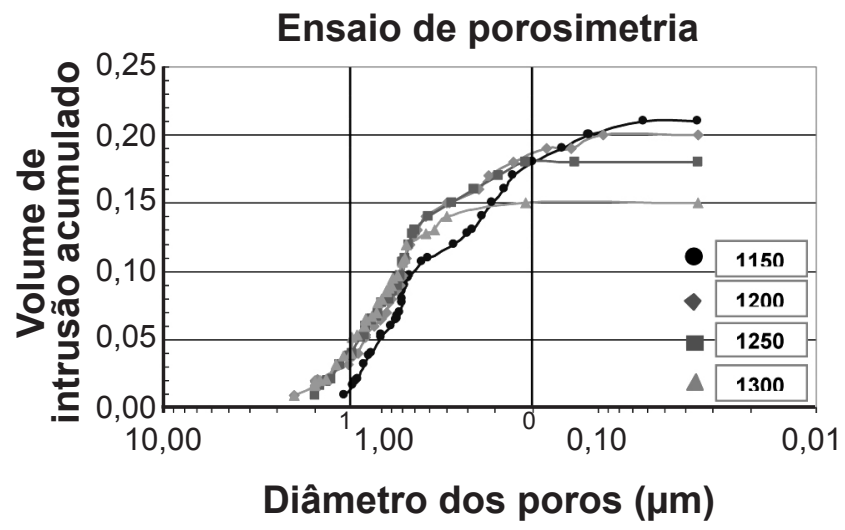

Figura 7: Variação do diâmetro dos poros em função do volume de intrusão de mercúrio acumulado nas membranas, composição 1.

[Figure 7: Pore size distribution as a function of mercury intrusion volume for the membranes, composition 1.] confirmando os resultados obtidos na análise granulométrica.

Os valores do diâmetro médio dos poros e da porosidade das membranas cerâmicas e sua relação com a temperatura na etapa de sinterização são apresentados na Tabela II, Figs. 8 e 9 .

De acordo com a Tabela II e a Fig. 8, a elevação da Tabela II - Valores do diâmetro médio dos poros e da porosidade das membranas de cerâmica sinterizadas a 1150 , 1200,1250 e $1300{ }^{\circ} \mathrm{C}$.

[Table II - Pore size and porosity of the ceramic membranes sintered at $1150,1200,1250$ and $1300{ }^{\circ} \mathrm{C}$.]

\begin{tabular}{ccc}
\hline $\begin{array}{c}\text { Temperatura de } \\
\text { Sinterização }\left({ }^{\circ} \mathrm{C}\right)\end{array}$ & $\begin{array}{c}\text { Diâmetro Médio } \\
\text { dos Poros }(\mu \mathrm{m})\end{array}$ & $\begin{array}{c}\text { Porosidade } \\
(\%)\end{array}$ \\
\hline 1150 & 0,58 & 38 \\
1200 & 0,76 & 37 \\
1250 & 0,87 & 35 \\
1300 & 1,09 & 31 \\
\hline
\end{tabular}

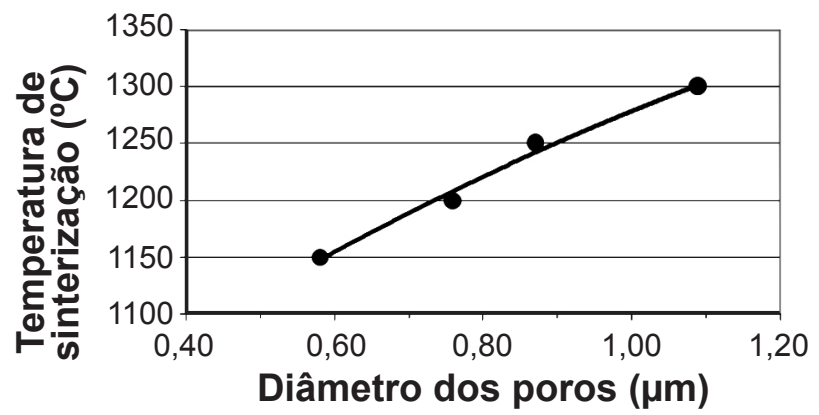

Figura 8: Relação entre temperatura de sinterização e diâmetro dos poros nas membranas cerâmicas.

[Figure 8: Relationship between sintering temperature and pore size in ceramic membranes.]

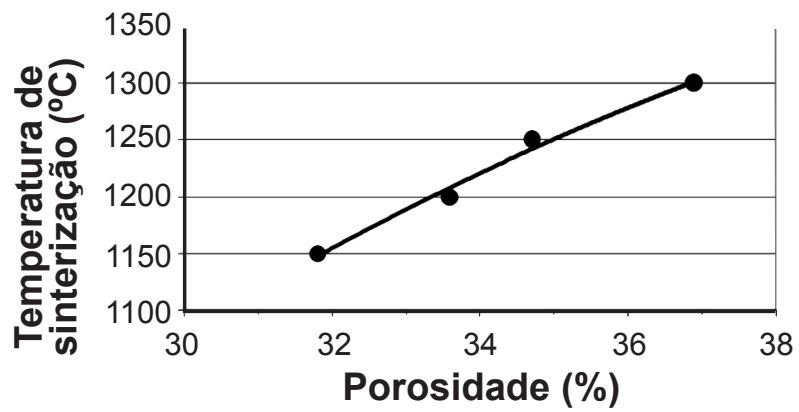

Figura 9: Relação entre temperatura de sinterização e porosidade nas membranas cerâmicas.

[Figure 9: Relationship between sintering temperature and porosity in ceramic membranes.]

temperatura na etapa de sinterização provocou aumento no diâmetro médio dos poros das membranas cerâmicas. Isto se deve provavelmente à formação de fase líquida durante a etapa de sinterização. À medida que se aumenta a temperatura de sinterização, mais fase líquida vai sendo formada. A formação de fase líquida leva ao crescimento 
de grãos e coalescência de poros [10]. Além disso, pode ter ocorrido solubilidade líquida no sólido levando a um processo de aumento do tamanho dos poros. A porosidade das membranas cerâmicas está entre 31 e $38 \%$ e de acordo com a Fig. 9, o aumento da temperatura de sinterização provocou diminuição da porosidade, já que à medida que se eleva a temperatura de sinterização ocorre mais formação de fase líquida e, conseqüentemente, mais eliminação dos pequenos poros, levando a diminuição da porosidade.

Os resultados dos fluxos de água destilada permeadas pelas membranas cerâmicas sinterizadas a 1150, 1200, 1250 e $1300{ }^{\circ} \mathrm{C}$ estão ilustrados na Fig. 10. Foram analisadas 3 amostras para cada temperatura de sinterização, sendo cada curva a média das três análises.

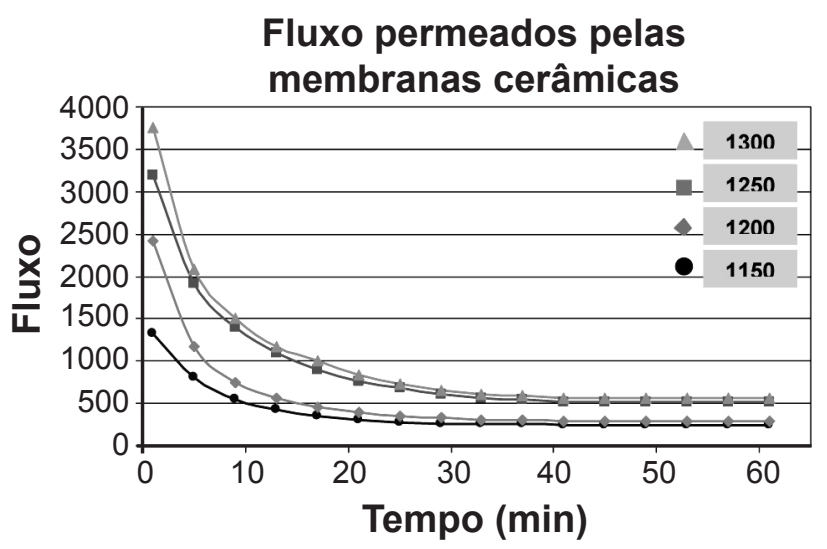

Figura 10: Valores comparativos da média dos fluxos de água destilada permeados pelas membranas cerâmicas.

[Figure 10: Comparative values of the average flow of desalinated water permeated by ceramic membranes.]

A membrana que obteve maior fluxo foi a sinterizada a $1300{ }^{\circ} \mathrm{C}$, seguindo-se $1250{ }^{\circ} \mathrm{C}, 1200{ }^{\circ} \mathrm{C}$ e $1150{ }^{\circ} \mathrm{C}$. Os fluxos permeados com água destilada pelas membranas cerâmicas diminuíram ao longo do tempo até atingir um valor constante a partir de $\sim 25$ min de operação. Neste ponto diz-se que o sistema atingiu o "estado estável", no qual o fluxo de água destilada é tomado como referência para a membrana estudada. Os valores médios dos fluxos permeados pelas membranas cerâmicas são mostrados na Tabela III.

As Figs. 11 e 12 mostram a relação entre fluxo permeado, temperatura de queima na fase de sinterização e diâmetro

Tabela III - Valores médios dos fluxos permeados pelas membranas cerâmicas no estado estável.

[Table III - Mean values of flows permeated by ceramic membranes at steady state.]

\begin{tabular}{cc}
\hline $\begin{array}{c}\text { Temperatura } \\
\text { de sinterização }\left({ }^{\circ} \mathrm{C}\right)\end{array}$ & $\begin{array}{c}\text { Fluxo permeado } \\
\left(\mathrm{kg} / \mathrm{h} \cdot \mathrm{m}^{2}\right)\end{array}$ \\
\hline 1150 & 244,1 \\
1200 & 290,3 \\
1250 & 515,5 \\
1300 & 563,6 \\
\hline
\end{tabular}

médio de poros das membranas cerâmicas das composições 1 e 2, respectivamente. De acordo com a Fig. 11 o aumento da temperatura na etapa de sinterização provocou aumento no diâmetro médio dos poros com conseqüente aumento no fluxo permeado. A Fig. 12 mostra a relação entre fluxo permeado, temperatura de queima na fase de sinterização e porosidade das membranas cerâmicas. Observa-se que o aumento da temperatura na etapa de sinterização provocou diminuição da porosidade, porém aumento do fluxo permeado, mostrando que o fluxo permeado é mais influenciado pelo tamanho dos poros do que pela própria porosidade. Este fenômeno pode ser analisado baseandose na equação de Hagen-Poiseuille, que mostra que o fluxo é diretamente proporcional a porosidade e ao quadrado do raio do poro, levando-se em consideração que os poros são interconectados e com formatos cilíndricos:

$$
J=\frac{\varepsilon \times r^{2}}{8 \times \eta \times \tau} \times \frac{\Delta P}{\Delta x}
$$

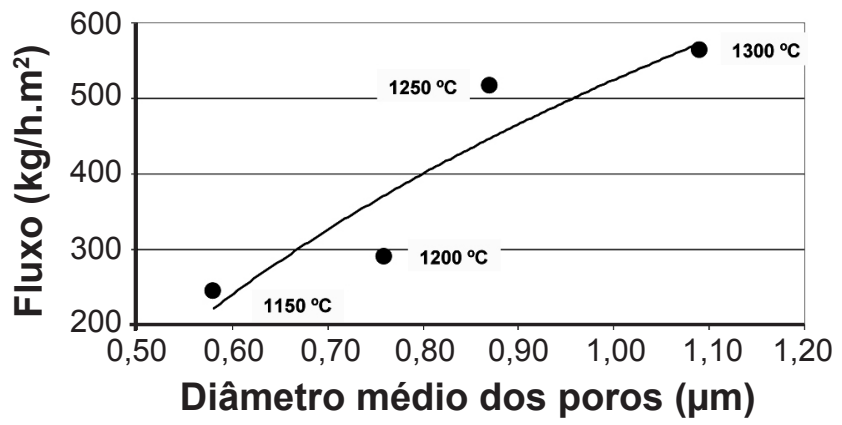

Figura 11: Relação entre fluxo permeado, diâmetro médio dos poros e temperatura de sinterização.

[Figure 11: Relationship between permeate flux, pore diameter and sintering temperature.]

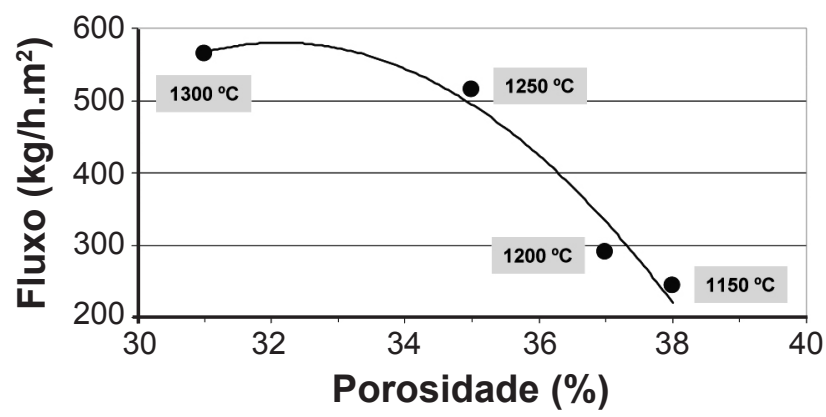

Figura 12: Relação entre fluxo permeado, porosidade e temperatura de sinterização.

[Figure 12: Relationship between permeate flux, porosity and sintering temperature.]

\section{CONCLUSÕES}

Membranas cerâmicas tubulares foram preparadas com sucesso e com tamanho de poros na faixa de microfiltração $(0,58$ a $1,09 \mu \mathrm{m})$. A elevação da temperatura na etapa de sinterização provocou aumento no diâmetro médio dos poros 
e uma diminuição na porosidade das membranas cerâmicas. O fluxo com água destilada foi maior para as membranas cerâmicas sinterizadas em temperaturas de sinterização mais elevadas, nas quais o aumento do tamanho dos poros teve mais influência do que a redução na porosidade.

\section{AGRADECIMENTOS}

Ao $\mathrm{CNPq}$ pelo suporte financeiro. Ao Laboratório de Referência em Dessalinização (LABDES) do Centro de Ciências e Tecnologia da UFCG, pelo uso de suas instalações e apoio à pesquisa.

\section{REFERÊNCIAS}

[1] F. A. Silva, H. L. Lira, Cerâmica 52 (2006) 276-282.

[2] A. J. Burggraaf, L. Cot, "Fundamentals of Inorganic Membranes, Science and Technology", $1^{\text {st }}$ Ed., Elsevier, Amsterdam, Holanda (1996).

[3] B. Elyassi, M. Sahimi, T. T. Tsotsis, J. Membrane Sci. 316 (2008) 73-79.

[4] M. R. Weir, E. Rutinduka, C. Detellier, C. Y. Feng, Q. Wang, T. Matsuura, R. Le Van Mao, Fabrication, characterization and preliminary testing of all-inorganic ultrafiltration membranes composed entirely of a naturally occurring sepiolite clay mineral, J. Membrane Sci. 182 (2001) 41-50.

[5] F. A. Silva, Desenvolvimento de membranas cerâmicas tubulares a partir de matérias-primas regionais para processo de microfiltração, Tese Dr. Engenharia de Processos, Centro de Ciências e Tecnologia, Universidade Federal de Campina Grande, Campina Grande, PB (2009) $146 f$.

[6] M. Oliveira, N. P. Barbosa, Potencialidades de um caulim calcinado como material de substituição parcial do cimento portland em argamassas. Rev. Bras. Eng. Agr. Amb. 10 (2006) 490-496.

[7] R. R. Menezes, M. M. Ávila Jr., L. N. L. Santana, G. A. Neves, H. C. Ferreira, Comportamento de expansão de argilas bentoníticas organofílicas do estado da Paraíba, Cerâmica 54 (2008)152-159.

[8] R. C. O. Lima, H. L. Lira, G. A. Neves, M. C. Silva, C. D. Silva, Aproveitamento do resíduo de serragem de granito para fabricação de membranas cerâmicas de baixo custo, Rev. Elet. Mater. Proc. 6 (2011) 163-169.

[9] M. Mulder, "Basic Principles of Membrane Technology", $1^{\text {st }}$ Ed., Kluwer Acad. Publ., Holanda (1991) 75.

[10] R. M. German, "Sintering, Theory and Practice", John Wiley \& Sons, New York, EUA (1996).

(Rec. 12/04/2013, Ac. 27/04/2013) 